\title{
Present Status of Research on the Regenerative Potential of Dental Pulp Stem Cells in Malaysia: A Systematic Review
}

\author{
Wong Mun Xuan ${ }^{1}$, Khoo Chiann $^{1}$, Md. Sanower Hossain ${ }^{2,3}$, Muhamad Fareez Ismail ${ }^{4}$, Nazmul Haque ${ }^{4,5, *(0)}$
}

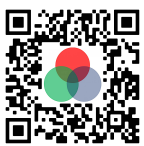

Use your smartphone to scan this QR code and download this article

${ }^{1}$ Faculty of Dentistry, MAHSA

University, Selangor, Malaysia

${ }^{2}$ Department of Biomedical Science, Kulliyyah (Faculty) of Allied Health Sciences, International Islamic University Malaysia (IIUM), Kuantan, Pahang, Malaysia

${ }^{3}$ Department of Biological Sciences, Faculty of Science, Sristy College of Tangail, 1900 Tangail, Bangladesh

${ }^{4}$ Department of Oral Biology and Biomedical Sciences, Faculty of Dentistry, MAHSA, University, Selangor, Malaysia

${ }^{5}$ TotiCell Ltd., Dhaka-1209, Bangladesh

Correspondence

Nazmul Haque, Department of Ora Biology and Biomedical Sciences, Faculty of Dentistry, MAHSA, University, Selangor, Malaysia

TotiCell Ltd., Dhaka-1209, Bangladesh

Email: tanna.bge@gmail.com; nazmul@mahsa.edu.my

History

- Received: 2021-01-07

- Accepted: 2021-03-01

- Published: 2021-04-30

DOI : 10.15419/psc.v8i1.410

\section{Check for updates}

\section{Copyright}

(c) Biomedpress. This is an openaccess article distributed under the terms of the Creative Commons Attribution 4.0 International license.

ABSTRACT

Stem cells from human exfoliated deciduous teeth (SHED) or dental pulp stem cells (DPSCs) from permanent teeth are considered promising sources of mesenchymal stem cells. It requires a less invasive technique to isolate stem cells from exfoliated or permanent teeth. Hence this study aimed to identify the present status of research on the regenerative potential of SHED/DPSCs in Malaysia. The results indicate that only 60 articles were published in regenerative medicine from Malaysia till $5^{\text {th }}$ July 2019 . Only 16 tertiary institutes and four industries/clinics were involved in these studies. A poor pattern of collaboration has also been identified. Outcomes of this study have emphasized the conduction of more research on the regenerative potential of SHED/DPSCs, and active collaboration among the tertiary institutes and industries for successful translation of these cells from bench side to bedside.

Key words: awareness, collaboration, differentiation, DPSC, regenerative medicine, SHED

\section{INTRODUCTION}

Chronic disease and disability are becoming more prevalent worldwide with a rapid increase in life expectancy $^{1,2}$. A similar scenario is observed in Malaysia. In the last 55 years, Malaysian people's life expectancy increased substantially from 54.3 years to 74.75 years $^{3,4}$. Meanwhile, the prevalence of several degenerative and non-communicable diseases like acute myocardial infarction, stroke, diabetes, spinal cord injuries, Alzheimer's disease, Parkinson's disease, among others, also increased gradually ${ }^{3}$. Cellbased regenerative therapy has shown its potential in treating these non-communicable or degenerative diseases. Embryonic stem cells (ESCs) and induced pluripotent stem cells (iPSCs) are considered the best sources of stem cells as they have pluripotency. However, the ethical concern over the use of ESCs ${ }^{5}$, and donors' fear towards the invasive techniques and/or donor site morbidity during collection of tissues for iPSCs generation limiting the clinical uses of these cells 6,7 .

The multipotent adult or post-natal mesenchymal stem cells (MSCs) have also received surging interest in the last two decades especially because of their immunomodulatory properties ${ }^{8,9}$. Among different sources of MSCs, isolation of dental pulp stem cells from human exfoliated deciduous teeth (SHED) and permanent teeth (DPSCs) are less invasive and pose no risk to the donors ${ }^{10,11}$.
DPSCs have drawn considerable attention just after their discovery by Gronthos et al. in the year $2000^{12}$, and several researches have been reported their potential to differentiate into different types of cell lineages such as cardiomyocytes, beta cells, hepatocytes, neuronal cells etc. ${ }^{10,13-16}$. Their MSCs like characteristics and immunomodulatory properties have also been acknowledged by several researchers ${ }^{11,17}$. Furthermore, SHED/DPSCs originate from the neural ectoderm that could provide additional benefits during tissue regeneration by promoting crucial neural innervation ${ }^{18,19}$. Besides, the higher osteogenic and chondrogenic differentiation potential of SHED/DPSCs could provide additional benefits during skeletal tissue regeneration ${ }^{20}$. Because of these properties, SHED/DPSCs could be great sources of autologous or allogeneic stem cells for regenerative therapy.

However, there is a lack of information on the status of SHED/DPSCs based research in Malaysia. Hence, in this study, we have attempted to identify the number of articles published on the SHED and/or DPSCs based researches in Malaysia. Besides, we have tried to determine the specific fields of studies conducted using SHED/DPSCs and collaborations (national and international) among the researchers working on these stem cells from different institutes in Malaysia.

\section{METHODS}

Cite this article : Xuan W M, Chiann K, Hossain M S, Ismail M F, Haque N. Present Status of Research on the Regenerative Potential of Dental Pulp Stem Cells in Malaysia: A Systematic Review. Progress Stem Cel.; 8(1):304-309. 


\section{Literature search strategy}

This systematic review was reported according to the recommendations of the Preferred Reporting Items for Systematic Reviews and Meta-analyses (PRISMA) Statement ${ }^{21}$. To achieve this study's goal, we conducted a comprehensive electronic literature search using PubMed and Scopus databases from their inception to 5 July 2019 . The following search terms were used for PubMed and Scopus databases: dental pulp stem cells [Title/Abstract] OR stem cells from human extracted deciduous teeth [Title/Abstract] OR stem cells from human exfoliated deciduous teeth [Title/Abstract]) AND Malaysia [Affiliation].

\section{Literature selection and data extraction}

Included studies have to satisfy all of the following inclusion criteria: (1) original research, (2) dental pulp stem cell source is human only, (3) at least one co-author of a manuscript is affiliated to one of the Malaysian institute or organization.

Based on the criteria mentioned above, two investigators independently reviewed each eligible literature and independently extracted the data. Any disagreements between these two investigators were resolved by consensus through a third investigator. The following data were extracted from each study: the last name of the first author, year of publication, study type, source of the cells, and specific field of study, affiliated institutes, and types of collaboration.

\section{Data analysis}

Following the data extraction, the number of articles contributed to each field of regenerative medicine, the total number of articles contributed by the individual organization and their pattern of collaboration (national/ international) were identified.

\section{RESULTS}

\section{Search Results}

The final selection process is shown in Figure 1. Briefly, a total of 120 articles were initially retrieved (Supplementary 1 and 2). After the removal of duplicates, 77 articles remained. Of which, 10 reviews and 2 errata were removed after reviewed the titles and abstracts. The remaining 65 articles were retrieved for full-text assessment. After reviewing the full-text, 5 articles were further removed as the source of dental pulp stem cells was non-human. Finally, 60 articles were included in this study (Figure 1). It has been observed that studies on the regenerative potential of SHED/DPSCs started publishing from 2009 only in Malaysia.

\section{Area of studies}

Analysis of data has revealed that researches conducted in Malaysia using SHED/DPSCs from human sources cover 17 fields, namely morphology/proliferation, immunomodulation, neuronal differentiation, material compatibility, osteogenesis, thrombopoiesis, angiogenesis, alopecia, tissue remodelling, dentinogenesis, cardiogenesis, chondrogenesis, hepatocyte differentiation, islets regeneration, notch signaling, reprogramming, cementoblast differentiation. Out of 17 fields, studies on morphology/proliferation (28.3\%) and material compatibility $(21.7 \%)$ contributed half of all the studies, followed by studies on neuronal differentiation (15\%) and immunomodulation (10\%). While, other major fields of regenerative medicine such as angiogenesis, cardiogenesis, hepatocyte differentiation, islets like differentiation, thrombopoiesis, tissue remodeling, and reprogramming received very little consideration and contributed one article each (Figure 2).

\section{Organizations involved and their pattern of collaboration}

From the further analysis, it has been found that only 16 individual tertiary institutions (University, University College, or medical college), three industries, and one clinic were involved in dental pulp stem cell-based regenerative studies during the mentioned period of time. Among all the identified institutes/organizations, only 9 have published papers with international collaboration. Surprisingly, two institutes, namely UMP and Sunway, have no national collaborative publication but international. Furthermore, except university of Malaya (UM), Universiti Sains Malaysia (USM), and Universiti Kebansaan Malaysia (UKM) number of total articles contributed by the institutes or organizations was equal to the number of articles published through either national or international collaboration (Figure 3). Out of 60 articles, almost $17 \%$ of articles [USM (8.33\%), UM (5\%), and UKM (3.33\%)] were published without any collaboration.

\section{DISCUSSION}

In the last two decades, numerous studies have been conducted to reveal the regenerative potential of MSCs. Despite sharing the characteristics of MSCs, needing less invasive techniques to isolate, and having a large donor pool SHED/DPSCs received very little attention in the field of regenerative medicine ${ }^{11}$. In this study, we were able to identify only 60 articles published in the field of regenerative medicine 


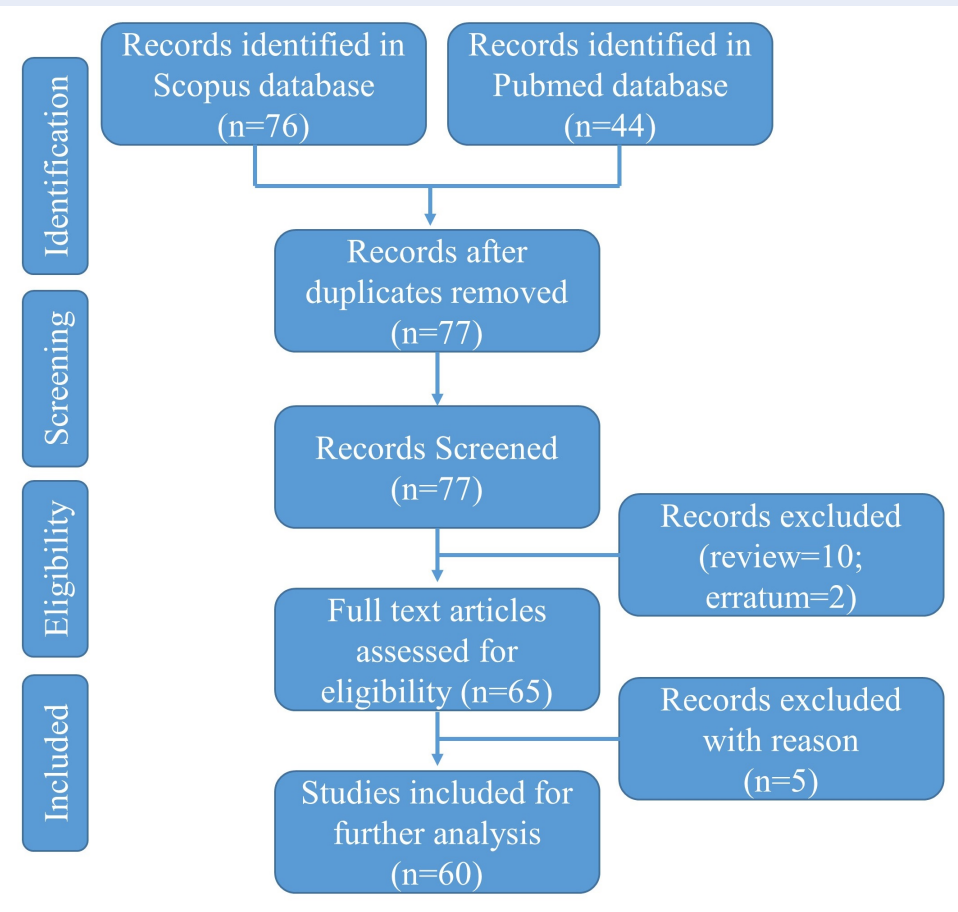

Figure 1: Summary of systemic search and screening of articles for inclusion in this study (Data collected till 5th July 2019).

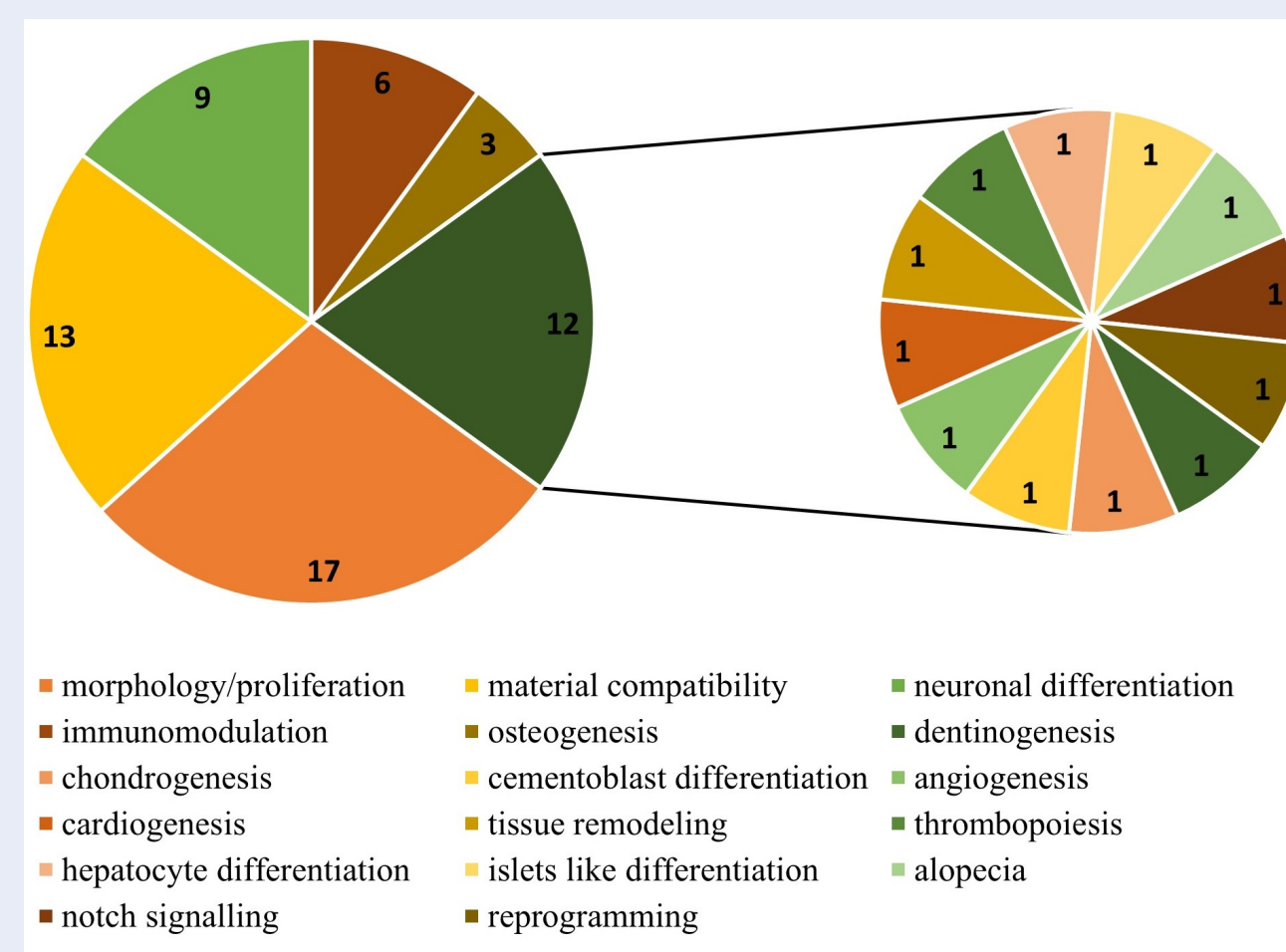

Figure 2: Area of studies covered by the researches on the regenerative potential of dental pulp stem cells from human exfoliated deciduous teeth (SHED) and permanent teeth (DPSCs) in Malaysia. 


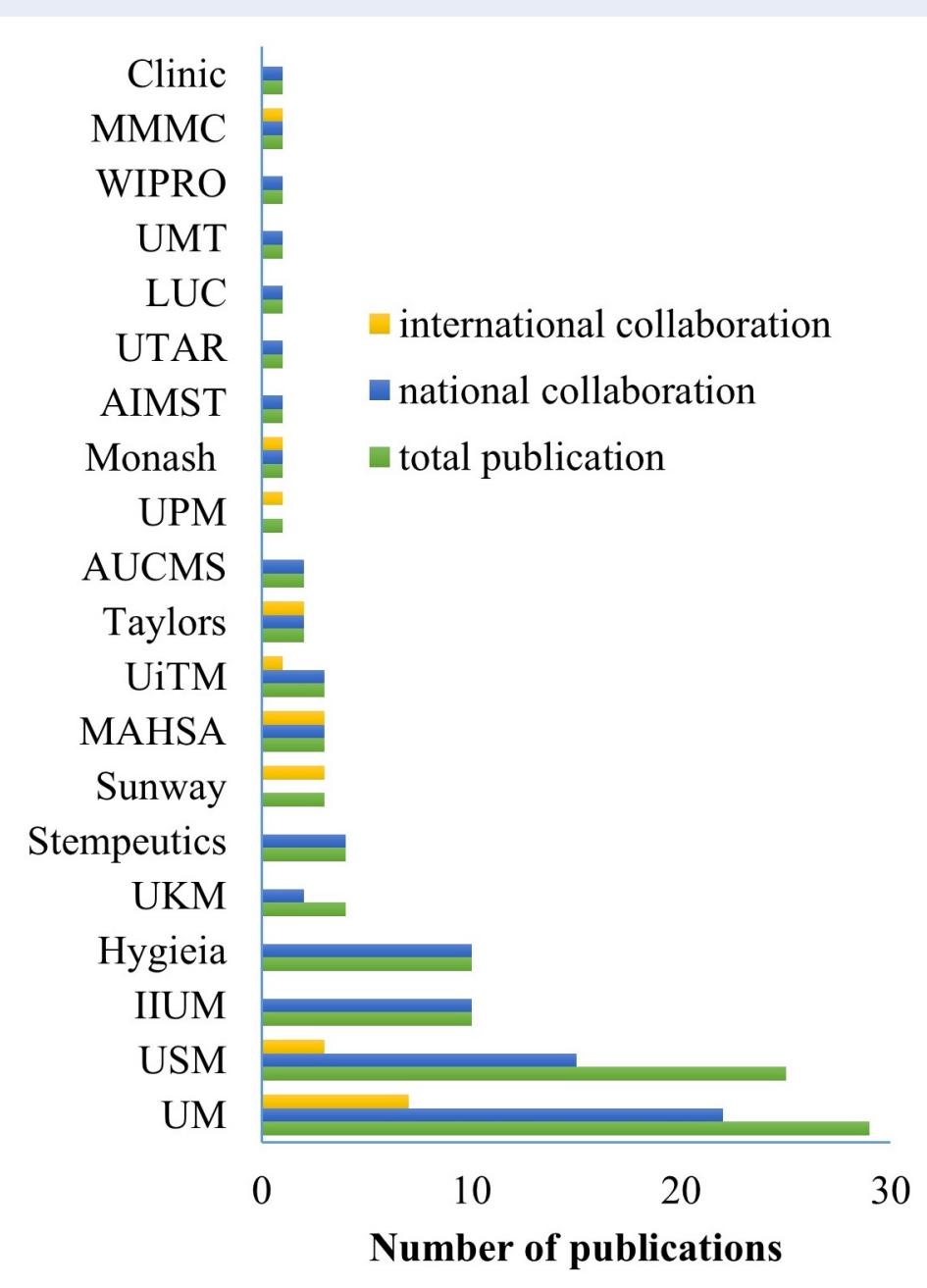

Figure 3: Organizations involved in dental pulp stem cell-based regenerative studies and their pattern of collaborations (UM, University of Malaya; USM, Universiti Sains Malaysia; IIUM, International Islamic University Malaysia; Hygiea, Hygieia Therapeutics Sdn Bhd; UKM, Universiti Kebangsaan Malaysia; Stempeutics, Stempeutics Research Malaysia Sdn. Bhd.; Sunway, Sunway University; MAHSA, MAHSA University; UiTM, University Technology Mara; Taylors, Taylors University; AUCMS, Allianze University College of Medical Sciences; UPM, University Putra Malaysia; Monash, Monash University; AIMST, AIMST University; UTAR, Universiti Tunku Abdul Rahman; LUC, Lincoln University College; UMT, University Malaysia Terengganu; WIPRO, WIPRO Manufacturing Services Sdn Bhd; MMMC, Melaka-Manipal Medical College).

using SHED/DPSCs from Malaysia. The use of SHED/DPSCs in a clinical trial is also very poor worldwide. As per the information on https://clinic altrials.gov/ (retrieved on 14 July 2020), out of 1063 registered clinical trials using MSCs only 21 are being contributed by SHED/DPSCs. While, out of eight registered clinical trials using MSCs in Malaysia, none is on SHED/DPSCs (Supplementary 3).

Lack of awareness of people, including dentists and researchers, about the regenerative potential of SHED/DPSCs might cause less attention by the scientific community. Poor knowledge on stem cells and their potential uses in dentistry among dental graduates in Saudi Arabia has been recently published ${ }^{22}$. Another study conducted in Nigeria also reported that the majority $(60.3 \%)$ of the dentists had poor knowledge of stem cells' potential in regenerative dentistry ${ }^{23}$. Whereas, in India, only $53.9 \%$ of dental professionals found to have awareness about the regenerative potential of stem cells from the dental origin $^{24}$. In contrast, about $81.5 \%$ of Malaysian medical students were aware of umbilical cord stem cells compared to stem cells from other sources ${ }^{25}$. This could be linked to the commercialized banking of um- 
bilical cord stem cells over the last decades all over the world, including Malaysia. Therefore, it can be postulated that the lack of knowledge and awareness about the regenerative potential of SHED/DPSCs among the health practitioners could be one of the major causes behind its being unpopular in the scientific community.

Interestingly, studies conducted on the interest and attitude towards the use of stem cells in regenerative therapy received a highly positive response from the dentists in South Africa (73\%) and nursing students in USM $(76.1 \%)^{26,27}$. As, several in vitro and in vivo studies have shown the regenerative potential of SHED/DPSCs (to cure or improve the condition of diseases, such as type 1 diabetes, neurological diseases, immunodeficiency diseases, and diseases of bone and cartilages) ${ }^{10,13-16,28}$, researchers should take the initiatives to explore the potential of SHED/DPSCs. Dentists or physicians are needed to explain the potential of SHED/DPSCs to the patients to make them aware of their presence.

Involvement of the tertiary institutes and stem cell industries in Malaysia in SHED/DPSCs based researches is also very low. This also could be linked to the lack of awareness and availability of funding as well. A poor pattern of collaboration identified in this study indicates the inefficient technology and knowledge transfer among the researchers from the different institutes within the country and abroad.

There are several limitations in this study. Firstly, we have collected the information from two databases only. Besides that, information on the funding body and first and corresponding authors were not recorded in this study that has affected to find the real nature of the collaborations. These should be considered in future studies to understand better and draw a proper conclusion.

\section{CONCLUSION}

Based on the result of this current study, it can be concluded that a very small number of researches on the regenerative potential of SHED/DPSCs have been conducted in different universities and research organizations in Malaysia. Most of the organizations have shown a poor pattern of collaboration that indicates a lack of communication among the experienced and skilled personnel of this field resides in Malaysia. The pattern of international collaboration was also very poor in this field. Studies on the regenerative potential of SHED/DPSCs are needed to be more emphasized.

\section{ACKNOWLEDGMENTS}

The authors would like to thank Umme Salma for reviewing this manuscript.

\section{FUNDING}

This work was supported by MAHSA University Grant, RP158-05/19.

\section{CREDIT AUTHORSHIP CONTRIBUTION STATEMENT}

Wong Mun Xuan: Methodology, Formal analysis, Writing - original draft. Khoo Chiann: Methodology, Formal analysis, Writing - original draft. Md. Sanower Hossain: Conceptualization, Writing - review \& editing. Muhamad Fareez Ismail: Formal analysis, Writing - original draft, Writing - review \& editing. Nazmul Haque: Conceptualization, Methodology, Formal analysis, Writing - original draft, Writing - review \& editing.

\section{DECLARATION OF COMPETING INTEREST}

The authors declared that there is no conflict of interest.

\section{REFERENCES}

1. Maiese K. Targeting molecules to medicine with mTOR, autophagy and neurodegenerative disorders. Br J Clin Pharmacol. 2016;82(5):1245-1266. PMID: 26469771. Available from: https://doi.org/10.1111/bcp.12804.

2. Wang $H$, Naghavi M, Allen C, Barber RM, Bhutta ZA, Carter A, et al. Global, regional, and national life expectancy, allcause mortality, and cause-specific mortality for 249 causes of death, 1980-2015: a systematic analysis for the Global Burden of Disease Study 2015. The Lancet. 2016;388(10053):1459544;Available from: https://doi.org/10.1016/S0140-6736(16) 31012-1.

3. Yunusa NaM, Abd Manaf NH, Omar A, Juhdi N, Omar MA, Salleh M. Determinants of healthcare utilisation among the elderly in Malaysia. Institutions and Economies. 2017:115-140;.

4. Wahid SNS, Azemi SNAN, Rashid SA, Hilmi ZAG, Razak MR, Ghani PA, editors. Malaysian Life Expectancy by Gender and Ethnic Group: A Comparative Study2019; Singapore: Springer Singapore;Available from: https://doi.org/10.1007/978-98113-0203-9_31.

5. Ghosh D, Mehta N, Patil A, Sengupta J. Ethical issues in biomedical use of human embryonic stem cells (hESCs). Journal of Reproductive Health and Medicine. 2016;2:S37S47;Available from: https://doi.org/10.1016/j.jrhm.2016.09. 002 .

6. Lee J-H, Seo S-J. Biomedical Application of Dental TissueDerived Induced Pluripotent Stem Cells. Stem cells international. 2016;2016:9762465;PMID: 27597868. Available from: https://doi.org/10.1155/2016/2794510.

7. Huang C-Y, Liu C-L, Ting C-Y, Chiu Y-T, Cheng Y-C, Nicholson MW, et al. Human iPSC banking: barriers and opportunities. J Biomed Sci. 2019;26(1):87;PMID: 31660969. Available from: https://doi.org/10.1186/s12929-019-0578-x.

8. Wang LT, Jiang SS, Ting CH, Hsu PJ, Chang CC, Sytwu HK, et al. Differentiation of Mesenchymal Stem Cells from Human Induced Pluripotent Stem Cells Results in Downregulation of c-Myc and DNA Replication Pathways with Immunomodulation Toward CD4 and CD8 Cells. Stem Cells. 2018;36(6):90314;PMID: 29396902. Available from: https://doi.org/10.1002/ stem. 2795 . 
9. Bulati M, Miceli V, Gallo A, Amico G, Carcione C, Pampalone $M$, et al. The Immunomodulatory Properties of the Human Amnion-Derived Mesenchymal Stromal/Stem Cells Are Induced by INF- $\gamma$ Produced by Activated Lymphomonocytes and Are Mediated by Cell-To-Cell Contact and Soluble Factors. Frontiers in Immunology. 2020;11(54);PMID: 32117234 . Available from: https://doi.org/10.3389/fimmu.2020.00054.

10. Govindasamy V, Ronald VS, Abdullah AN, Nathan KR, Ab Aziz ZA, Abdullah $M$, et al. Differentiation of dental pulp stem cells into islet-like aggregates. J Dent Res. 2011;90(5):64652;PMID: 21335539. Available from: https://doi.org/10.1177/ 0022034510396879.

11. Haque N, Khan IM, Abu Kasim NH. Survival and immunomodulation of stem cells from human extracted deciduous teeth expanded in pooled human and foetal bovine sera. Cytokine. 2019;120:144-54;PMID: 31071675. Available from: https://doi. org/10.1016/j.cyto.2019.04.018.

12. Gronthos S, Mankani M, Brahim J, Robey PG, Shi S. Postnatal human dental pulp stem cells (DPSCs) in vitro and in vivo. Proc Natl Acad Sci U S A. 2000;97(25):13625-30;PMID: 11087820. Available from: https://doi.org/10.1073/pnas.240309797.

13. Yang X, Li L, Xiao L, Zhang D. Recycle the dental fairy's package: overview of dental pulp stem cells. Stem Cell Research \& Therapy. 2018;9(1):347;PMID: 30545418. Available from: https://doi.org/10.1186/s13287-018-1094-8.

14. Vasanthan P, Gnanasegaran N, Govindasamy V, Abdullah AN, Jayaraman P, Ronald VS, et al. Comparison of fetal bovine serum and human platelet lysate in cultivation and differentiation of dental pulp stem cells into hepatic lineage cells. Biochem Eng J. 2014;88(0):142-53;Available from: https://doi. org/10.1016/j.bej.2014.04.007.

15. Vasanthan $\mathrm{P}$, Jayaraman $\mathrm{P}$, Kunasekaran $\mathrm{W}$, Lawrence $\mathrm{A}$, Gnanasegaran N, Govindasamy V, et al. Generation of functional hepatocyte-like cells from human deciduous periodontal ligament stem cells. Naturwissenschaften. 2016;103(78):62;PMID: 27379400. Available from: https://doi.org/10. 1007/s00114-016-1387-7.

16. Gnanasegaran N, Govindasamy V, Mani V, Abu Kasim NH. Neuroimmunomodulatory properties of DPSCs in an in vitro model of Parkinson's disease. IUBMB Life. 2017;69(9):68999;PMID: 28685937. Available from: https://doi.org/10.1002/ iub.1655.

17. Andrukhov O, Behm C, Blufstein A, Rausch-Fan X. Immunomodulatory properties of dental tissue-derived mesenchymal stem cells: Implication in disease and tissue regeneration. World journal of stem cells. 2019;11(9):604-17;PMID: 31616538. Available from: https://doi.org/10.4252/wjsc.v11.i9. 604.
18. Liu J, Saul D, Böker KO, Ernst J, Lehman W, Schilling AF. Current Methods for Skeletal Muscle Tissue Repair and Regeneration. BioMed Research International. 2018;2018:1984879;PMID: 29850487. Available from: https://doi.org/10.1155/2018/ 1984879.

19. Yang J, Yuan G, Chen Z. Pulp Regeneration: Current Approaches and Future Challenges. Frontiers in Physiology. 2016;7(58);Available from: https://doi.org/10.3389/fphys.2016. 00058.

20. Park Y-J, Cha S, Park Y-S. Regenerative Applications Using Tooth Derived Stem Cells in Other Than Tooth Regeneration: A Literature Review. Stem Cells International. 2016;2016:9305986;PMID: 26798366. Available from: https: //doi.org/10.1155/2016/9305986.

21. Moher D, Liberati A, Tetzlaff J, Altman DG. Preferred reporting items for systematic reviews and meta-analyses: the PRISMA statement. BMJ. 2009;339:b2535;PMID: 19622551. Available from: https://doi.org/10.1136/bmj.b2535.

22. Alhadlaq A, Al-Maflehi N, Alzahrani S, AlAssiri A. Assessment of knowledge and attitude toward stem cells and their implications in dentistry among recent graduates of dental schools in Saudi Arabia. The Saudi Dental Journal. 2019;31(1):6675;PMID: 30705571. Available from: https://doi.org/10.1016/ j.sdentj.2018.10.006.

23. Sede MA, Audu O, Azodo CC. Stem cells in Dentistry: knowledge and attitude of Nigerian Dentists. BMC Oral Health 2013;13(1):27;PMID: 23767980. Available from: https://doi. org/10.1186/1472-6831-13-27.

24. Chitroda P, Katti G, Attar N, Shahbaz S, Sreenivasarao G, Patil A Stem cells in dentistry: A study regarding awareness of stem cells among dental professionals. Indian Journal of Dental Research. 2017;28(6):711-6;PMID: 29256476. Available from: https://doi.org/10.4103/ijdr.IJDR_771_16.

25. Kim DL, Ramasamy T, Amini F. Knowledge, awareness and perception of stem cells research amongst Malaysian medical students. Malay. 2016;31.

26. Basson R, Moodley D, Oliviera A, Basson N. A survey of the opinions of Dentists regarding stem cells in Dentistry. South African Dental Journal. 2016;71:351-355;.

27. Lye JL, Soon LK, Wan Ahmad WAN, Tan SC. Knowledge and Attitude about Stem Cells and Their Application in Medicine among Nursing Students in Universiti Sains Malaysia, Malaysia. The Malaysian journal of medical sciences : MJMS. 2015;22(4):23-31;.

28. Chalisserry EP, Nam SY, Park SH, Anil S. Therapeutic potential of dental stem cells. Journal of tissue engineering. 2017;8:2041731417702531;PMID: 28616151. Available from: https://doi.org/10.1177/2041731417702531. 